\title{
Oral Hygiene Knowledge among Medical and Dental Faculty
}

\author{
Ayesha lqbal ${ }^{1}$ Suraiya Hirani ${ }^{2} \quad$ Sarah Hanif ${ }^{2}$ Sandhiya Salim ${ }^{3}$
}

1Department of Oral Pathology, Sir Syed College of Medical Sciences, Karachi City, Karachi, Pakistan

2Department of Oral Biology, Sir Syed College of Medical Sciences, Karachi City, Karachi, Pakistan

${ }^{3}$ Department of Community Dentistry, Sir Syed College of Medical

Sciences, Karachi City, Karachi, Pakistan

\begin{abstract}
Address for correspondence Ayesha Iqbal, BDS, MSc-UK, Department of Oral Pathology, Sir Syed College of Medical Sciences, Karachi City, Karachi 75600, Pakistan (e-mail: ayeshaiqbal690@yahoo.com).
\end{abstract}

\begin{abstract}
Keywords

- oral hygiene

- faculty

- knowledge

Objective Oral health reflects the physical and mental health of the individual as it is the first line of entrance of bacteria into the body. Knowledge regarding oral health is an essential component for dental as well as medical faculty as they are responsible for maintenance of health of the individual in clinical and nonclinical practices. Therefore, the aim of the study was to determine the predominance of oral hygiene with dental brushing, flossing, smoking, usage of mouthwash, and frequency of dental visits.

Materials and Methods To achieve the aim of the study, a questionnaire was created to access the awareness of oral hygiene status among medical and dental faculty. The study was conducted at Sir Syed College of Medical Sciences and all the faculty staff from senior faculty to junior staff was included in the study.

Results A total of 200 participants participated in the study of which 125 were females (62.5\%). The results specify that the female faculty members have a better oral hygiene knowledge as compared with male faculty members. Single faculty members or staff visit a dentist more as compared with married faculty members or staff as single staff has more time and less responsibilities at home. Knowledge regarding oral hygiene care of overall participants is satisfactory.

Conclusion In conclusion, the oral health care and knowledge is far better in dental faculty member as compared with medical faculty member as the oral care is the substantial component of the dental core curriculum.
\end{abstract}

\section{Introduction}

Oral cavity is the first line of entrance for bacteria into the body. Its health affects the physical and mental aspects of general health. ${ }^{1}$ Oral disorders such as tooth loss can affect a person's social and personal life, thereby affecting his lifestyle and quality of life. The absence of illness and susceptibility showed only physical health, but according to the World Health Organization, health states social, physical, and mental wellbeing. ${ }^{2}$ From this aspect, the paramount goal of dentistry is not only the absence of dental diseases such as dental caries, periodontitis, and tooth loss but the overall health care of people. ${ }^{3}$ Maintenance of oral health care starts with the removal of the plaque deposits from the oral cavity. ${ }^{4}$ Studies done in Germans indicate that $90 \%$ of the population is suffering from gingivitis and 30 to $70 \%$ from periodontitis. ${ }^{5}$ Currently, $70 \%$ of the German population brush their teeth twice regularly indicating most people do not sufficiently remove their plaque deposits. These data show that deficits in oral hygiene are due to the lack of oral hygiene skills in people and they need to be educated for proper brushing techniques. ${ }^{6}$

Although brushing and flossing are the most common mechanical ways of oral hygiene maintenance in developed countries, the use of other practices such as miswak, a chewing stick made from the extract of Salvadora persica, is also 
common in Islamic countries. ${ }^{7,8}$ According to the American Dental Association, it is recommended that a person should brush his teeth twice daily with a soft bristled toothbrush for at least 2 minutes. ${ }^{9}$ In gingivitis and periodontitis, the close proximity of subgingival biofilm and highly inflamed gingival margin tissues, where the epithelium is ulcerated and the underlying connective tissue is highly vascularized, resulting in easy passage of bacteria into the blood circulation and their distant spread to other body organs. ${ }^{10}$ This mechanism contributes to be one of the key processes describing the relationship between periodontitis and systemic disorders. ${ }^{11}$

Halitosis commonly referred to as bad breath or malodor is associated with the mouth and the ability of gram-negative bacteria to decompose sulfur-containing substrates. ${ }^{12,13}$ Brushing with a toothpaste formulated with antimicrobial ingredients followed by rinsing with mouthwash may provide greater control of oral organisms within the residual plaque that remains inaccessible to tooth brushing. ${ }^{14}$ To secure a good oral hygiene eradicating gingivitis, calculus, plaque, and bleeding disorders, a comparative clinical study was done comprising $0.075 \%$ cetylpyridinium chloride mouth rinse and triclosan toothpaste in 2005. ${ }^{15}$

Clinically, the most important step is the evaluation of the disease and recognition of its root cause before the etiological factors detected. The mechanical interaction between tooth, toothbrush, and toothpaste often results in noncarious cervical lesions. Frictional forces affecting a tooth increases by the microparticles present in a toothpaste. ${ }^{16,17}$ The degree of abrasion can be modified by the type of brush used and the type of brushing technique used generating the appropriate amount of force on the tooth. ${ }^{18} \mathrm{~A}$ large number of different types of electric toothbrushes such as oscillating-rotating, sonic, and ultrasonic are now available in the market. Recent review studies suggest that power tooth brushes are comparatively less abrasive than the manual tooth brushes, thereby having less potential for damaging hard and soft tissues of a tooth. ${ }^{19,20}$

Evidences show that gingivitis in the proximities commences in the central area of the papilla. ${ }^{21-23}$ As this area is not fully stimulated by probing, the presence of gingivitis in proximal regions with an established point of contact might be underestimated. Dental flossing was first introduced as a diagnostic factor by Carter and Barnes. ${ }^{24}$ In contrast, from periodontal probing, it is found that flossing has a greater impact on detection of proximal gingivitis and is hypothesized that it is more accurate for diagnosis of proximal caries. Nutrition is another factor that is associated with oral health. Inadequate nutrition affects negatively on human growth and oral health. ${ }^{25} \mathrm{~A}$ vicious cycle continues to develop between poor nutrition and oral health; however, poor nutrition leads to poor oral hygiene and vice versa. ${ }^{26,27}$ Normal flora of the oral cavity act on fermentable sugars producing an acidic environment and causing dissolution of minerals present in dental tissues of the teeth, thereby causing dental caries. ${ }^{28,29}$

With already known researches done nationally and internationally, comparison of oral health knowledge among medical and dental faculty was not done. Therefore, the aim of the study was to determine the predominance of oral hygiene with dental brushing, flossing, smoking, usage of mouthwash, and frequency of dental visits.

\section{Materials and Methods}

This cross-sectional study was performed during the academic year of 2019 in which 200 medical and dental faculty members from senior position to junior staff participated. Senior staff includes professor, assistant professor, senior lecturer, whereas junior staff includes house officer and lecturer and lower staff includes technicians, assistants, librarian, etc. They were given a predesigned questionnaire for assessing their knowledge related to oral health. Sample collection was done in August 2019. Consent was taken from each participant before induction in the study. Sampling was done through convenience sampling technique and sample size was determined through OpenEpi, version 3, having 95\% confidence interval. A survey using a self-assessed questionnaire was made in disguise among the medical and dental faculty irrespective of designations to inquire into their oral health behavior, preventive care measures, and oral health perceptions. Questions in questionnaire was associated with basic oral hygiene care including when to brush, for how long to brush, when to visit dentist, and what should be done when initial cavitation lesion is to be found in oral cavity. The questionnaire was collected straightaway and data collected were tabulated and analyzed by using SPSS v.22.0 software. The oral hygiene attitudes and their concerns were compared between faculty of different medical and dental departments by using frequencies and percentages

\section{Approval from Authorities and Ethical Considerations}

Clearance through ethical approval letter from concerned authorities and individual consent was taken prior to study from ethical and review board of Sir Syed College of Medical Sciences. The study protocol was approved from the ethical committee of the institute and permission was granted for conducting the study.

\section{Results}

A total of 200 faculty members participated in the study of which $62.5 \%$ (125) were females and $37.5 \%$ (75) were males and the ratio of dental faculty members (54\%) was higher compared with medical faculty members. Senior faculty members including professor, associate professor, assistant professor, and senior registrar showed higher (42\%) frequency when compared to junior faculty members including lecturers and lower staff including assistants (-Table 1).

Out of 200 participants, $61.0 \%$ brush twice a day for 2 minutes (68.5\%), of which only $66.5 \%$ clean their tongue. The use of mouthwash and dental floss was not very common on daily basis as only 63.5 and $65.0 \%$ of the participants used them, respectively. From all the participants, $70.5 \%$ thought their oral hygiene was good as they visited dentist only when they had a problem (71.5\%). Knowledge regarding oral hygiene of the participants was satisfactory as initial carious lesions could be stopped using preventive 
10 Oral Hygiene Knowledge among Medical and Dental Faculty Iqbal et al.

Table 1 Frequency distribution of faculty members

\begin{tabular}{|l|l|l|l|}
\hline Variables & Mean \pm SD & Classification & Percentage \\
\hline \multirow{2}{*}{ Gender } & $1.37 \pm 0.485$ & Male & $75(37.5 \%)$ \\
\cline { 3 - 4 } & & Female & $125(662.5 \%)$ \\
\hline Marital status & $1.54 \pm 0.500$ & Married & $92(46 \%)$ \\
\cline { 3 - 4 } & & Single & $108(54 \%)$ \\
\hline Smoking & $1.90 \pm 0.301$ & Yes & $20(10 \%)$ \\
\cline { 3 - 4 } & & No & $180(90 \%)$ \\
\hline Status of faculty & $1.54 \pm 0.500$ & Medical & $92(46 \%)$ \\
\cline { 3 - 4 } & & Dental & $108(54 \%)$ \\
\hline Level of faculty & $1.84 \pm 0.811$ & Senior & $84(42 \%)$ \\
\cline { 3 - 4 } & & Junior & $64(32 \%)$ \\
\cline { 3 - 4 } & & Lower staff & $52(26 \%)$ \\
\hline
\end{tabular}

Abbreviation: SD, standard deviation.

Table 2 Frequency distribution of variables to access knowledge of oral hygiene

\begin{tabular}{|c|c|c|c|}
\hline Variables & Mean \pm SD & Classification & Percentage \\
\hline \multirow[t]{2}{*}{ How many times do you brush your teeth? } & \multirow[t]{2}{*}{$1.61 \pm 0.489$} & Once daily & $39 \%$ \\
\hline & & Twice a day & $61 \%$ \\
\hline \multirow[t]{2}{*}{ How much time do you take for each brushing? } & \multirow[t]{2}{*}{$1.69 \pm 0.466$} & $1 \mathrm{~min}$ & $31.5 \%$ \\
\hline & & $2 \min$ & $68.5 \%$ \\
\hline \multirow[t]{2}{*}{ Do you clean your tongue? } & \multirow[t]{2}{*}{$1.33 \pm 0.473$} & Yes & $66.5 \%$ \\
\hline & & No & $33.5 \%$ \\
\hline \multirow[t]{2}{*}{ Do you use floss? } & \multirow[t]{2}{*}{$1.65 \pm 0.478$} & Yes & $35 \%$ \\
\hline & & No & $65 \%$ \\
\hline \multirow[t]{2}{*}{ Do you use mouthwash? } & \multirow[t]{2}{*}{$1.64 \pm 0.483$} & Yes & $36.5 \%$ \\
\hline & & No & $63.5 \%$ \\
\hline \multirow[t]{4}{*}{ How much do you value your dental health? } & \multirow[t]{4}{*}{$1.86 \pm 0.631$} & Very good & $23.5 \%$ \\
\hline & & Good & $70.5 \%$ \\
\hline & & Bad & $2.0 \%$ \\
\hline & & I do not know & $4.0 \%$ \\
\hline \multirow{3}{*}{$\begin{array}{l}\text { According to you, a regular dental checkup } \\
\text { should be? }\end{array}$} & \multirow[t]{3}{*}{$1.48 \pm 0.795$} & Every 6 months & $52.5 \%$ \\
\hline & & Once a year & $18 \%$ \\
\hline & & When necessary & $29.5 \%$ \\
\hline \multirow[t]{3}{*}{ How often do you visit dentist? } & \multirow[t]{3}{*}{$1.77 \pm 0.878$} & When I have dental problem & $71.5 \%$ \\
\hline & & Once a year & $9.5 \%$ \\
\hline & & Twice a year & $19.0 \%$ \\
\hline \multirow{3}{*}{$\begin{array}{l}\text { What would you do if you come across initial } \\
\text { carious lesion? }\end{array}$} & \multirow[t]{3}{*}{$2.13 \pm 0.963$} & Take preventive measures & $40.5 \%$ \\
\hline & & Wait and watch & $6.0 \%$ \\
\hline & & Treat as soon as possible & $53.5 \%$ \\
\hline
\end{tabular}

Abbreviation: SD, standard deviation.

measures but according to participants, it should be treated as soon as possible (- Table 2 , - Figs. 1-7).

\section{Discussion}

Health professionals perform a crucial role in providing awareness regarding oral hygiene and its importance among public. Rising countries show absence of responsiveness toward dental care and poor oral hygiene habits among large sectors of the population and promoting increase risk of oral health problems. Ever since dentists are anticipated to be starring role to their patients, so the assessment of oral health of dentist's will always strongly inspire their advice to their patients in their self-care oral practices. ${ }^{14}$ Dental and medical faculty members hold high level of responsiveness of self-oral health care so that this approach can be introduced among patients and community at large. With 


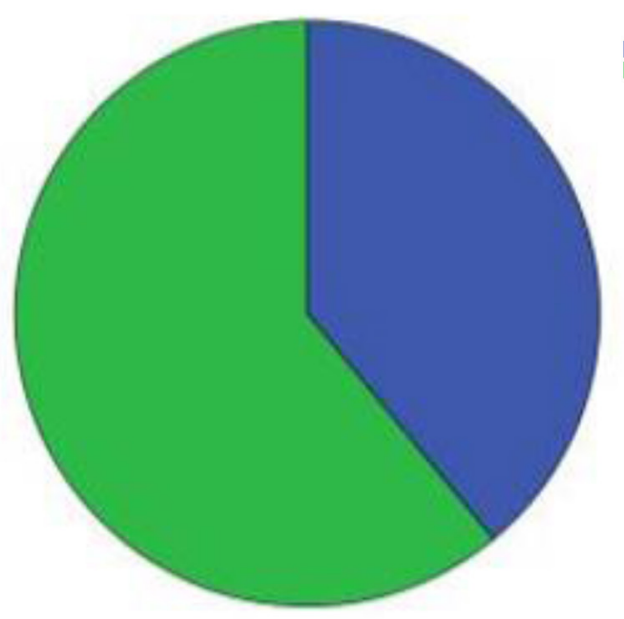

Fig. 1 How many times do you brush your teeth?

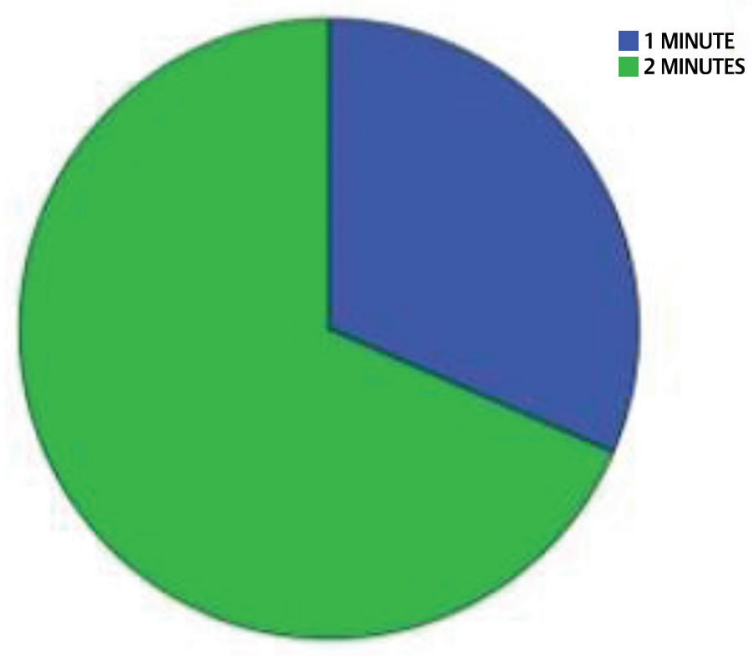

Fig. 2 How much time do you take for each brushing?

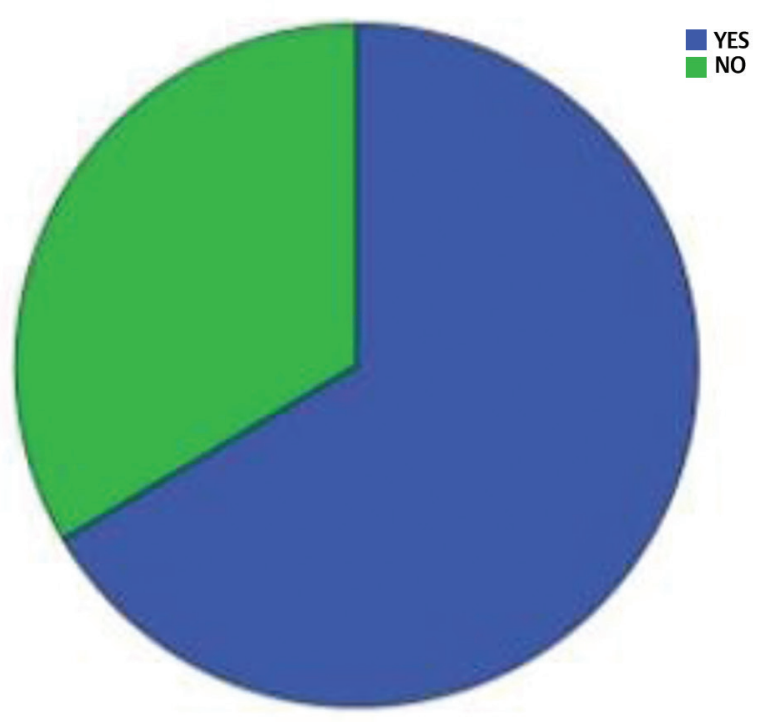

Fig. 3 Do you clean your tongue?

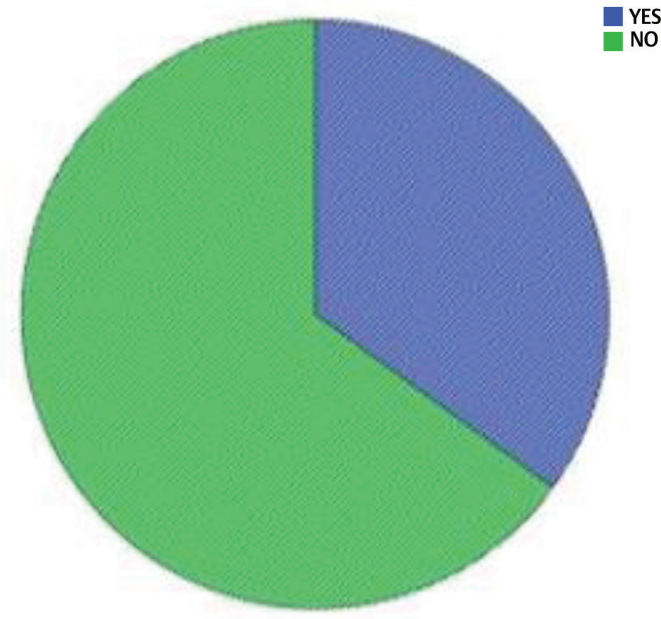

Fig. 4 Do you use floss?

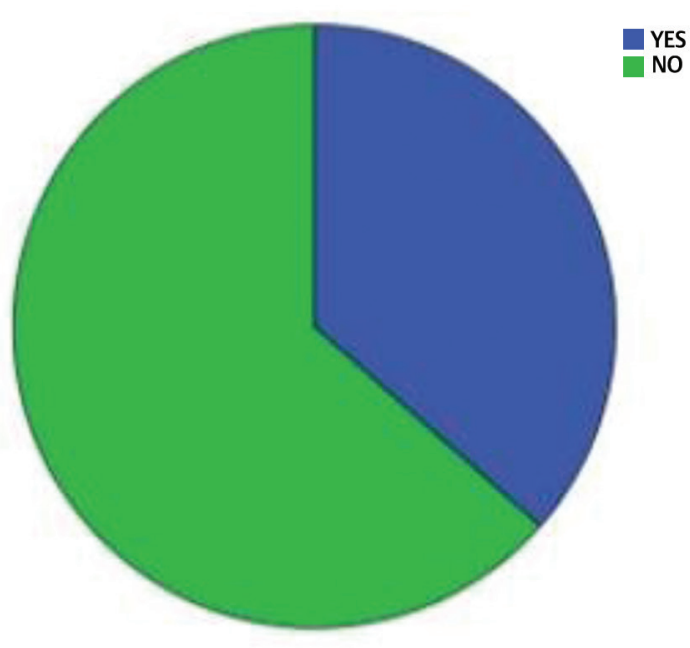

Fig. 5 Do you use mouthwash?

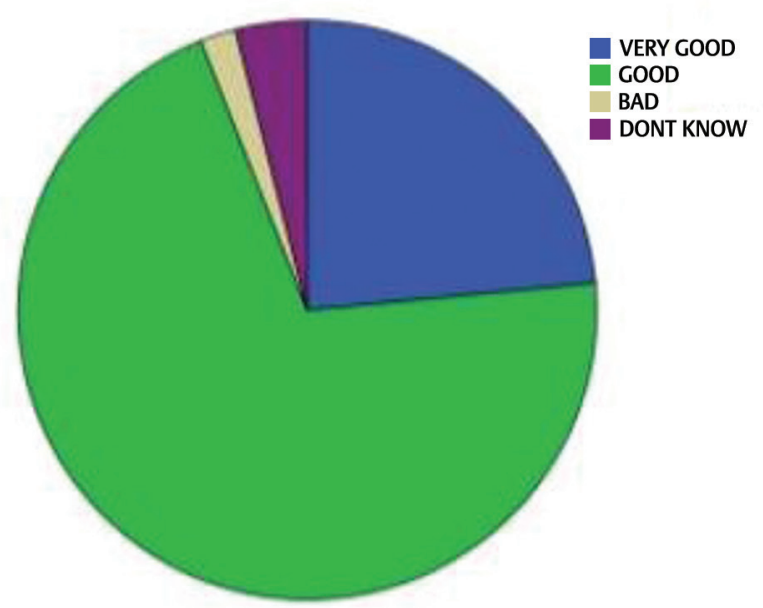

Fig. 6 How much do you value your dental health? 


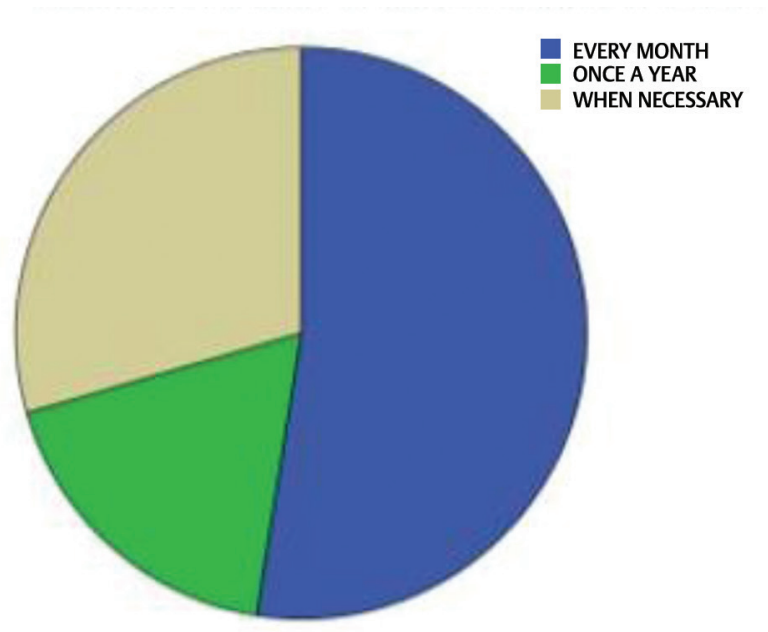

Fig. 7 According to you, a regular dental checkup should be?

regard of this valid reason keeping in mind, the existent research was principally done in view of the oral self-care and concepts among medical and dental staff. The forte of methodology in present study was that, it was the first formal assessment of oral hygiene knowledge, awareness, and their dental approach among dental and medical faculty steered in college with an ample sample size of maximum female strength. There were no controversies raised by the study.

The questionnaire which were distributed were based on nine observative questions based on brushing habits, use of dental floss, mouthwash, and dental treatments along with regular dental visits. The outcomes from this study indicate that utmost of the medical and dental staff maintains oral hygiene and brush their teeth for one reason or the other.

We planned to carry out our study in reference to other studies, but unfortunately, most of the studies were performed by collecting data on students. Our present study in correspondence to a study performed in Kanpur, India, was compared and evaluated that their medical faculty were more vigorous in maintaining oral hygiene paralleled to our study where the dental faculty were deliberating performing in oral hygiene practice. ${ }^{30}$

According to the outcome of our data, the results are calculated and clearly observed that the dental staff is more concerned and responsive about their self-oral hygiene maintenance. The ratio of genders was compared for the brushing habit, tongue cleanliness, use of mouthwash, floss, dental visits and for preventive measures. The final comparison among genders states that immense number of females are contrary more concerned to maintain their oral hygiene than the male gender ratio. This tendency might be due need for the aesthetic aspects. Another comparison was done between the dental and medical faculty members for the entire questionnaire mentioned earlier. ${ }^{31}$ The results imitate that the medical staff regardless of the hygiene concepts has low self-care oral practice as compared with dental staff. This inequality can be accredited to variation of opinion in oral self-care hygiene practices, as a concern of the present educational setup. Thus, these results shall be valid only for our study sample. The third comparison was evaluated among the levels of faculty including senior staff, junior staff, and lower staff, which concludes that the lower staff were least, concerned about their oral health. This might be due to lack of awareness and low income; relatively, the junior and senior staff were found to be well educated and positive about their regular dental visits and maintaining good oral hygiene. The last comparison was done between married and single overall faculty members which clarifies that the single members were active and show regular oral hygiene maintenance care, whereas the married members were not much involve in their self-care due to more responsibilities, respectively. ${ }^{32}$ The only limitation of this study is that the faculty members of the college was included not the students, plus the confidentiality is kept and scores are determined on self-reported data which could be over- or underreported due to social prestige. Additional research is needed to examine the periodontal condition and malodor due to negligence of dental checkup and treatment clinically and objectively by available standard procedures. Both the females and male faculty should be motivated to be a health symbol and keeping their mouth free from all bacterial pellicles.

\section{Conclusion}

In this study, we found that the oral health care and knowledge is far better in dental faculty member than compared with medical faculty staff as the oral care is substantial component of the dental core curriculum. The females and single members have a better oral hygiene and attribute toward health care than the males and married members who were found out to be irresponsive to take care of their teeth. Additional highlighting on oral health is required from lower to upper staff to develop the knowledge and self-care to maintain a healthy oral environment. These people will act as role models in future for providing dental and medical care among entities and community on large scale. Conversely, the total proportion of the personnel who follow the recommended self-care can still be amended. Altogether the dental staff and dental students, the forthcoming oral health providers, pave the mode for better society in the establishment of better oral hygienic conditions.

\section{Conflict of Interest}

None declared.

\section{References}

1 Slade GD, Spencer AJ. Development and evaluation of the oral health impact profile. Community Dent Health 1994;11(1):3-11

2 Grad FP. The Preamble of the Constitution of the World Health Organization. Bull World Health Organ 2002;80(12):981-984

3 Waller N, John MT, Feuerstahler L, et al. A 7-day recall period for a clinical application of the oral health impact profile questionnaire. Clinical oral investigations. 2016;20(1):91-99

4 Axelsson P, Nyström B, Lindhe J. The long-term effect of a plaque control program on tooth mortality, caries and periodontal disease in adults. Results after 30 years of maintenance. J Clin Periodontol 2004;31(9):749-757 
5 Hoffmann T, John M, Kerschbaum T, et al. Fourth German Oral Health Study (DMS IV). Cologne. Microcensus: Questions on health (2009a): Distribution of the population among body mass index groups in. 2006;31

6 Micheelis W, Reiter F. Sociodemographic and behavior related aspects of oral risk factors in four age cohorts (Soziodemographische und verhaltensbezogene Aspekte oraler Risikofaktoren in den vier Alterskohorten). Fourth German Oral Health Study (DMS IV) (Vierte Deutsche Mundgesundheitsstudie (DMS IV)) Köln: Deutscher Zahnärzte Verlag DÄ V; 2006:375-398

7 Morales-Suárez-Varela M, Ibáñez-Cabanell P, Gimeno-Clemente N, Roig-García JM, Nieto-García MA, Llopis-González A. Oral and dental health of non-institutionalized elderly people in Spain. Arch Gerontol Geriatr 2011;52(2):159-163

8 Aboul-Enein BH. The miswak (Salvadora persica L.) chewing stick: Cultural implications in oral health promotion. The Saudi Journal for Dental Research 2014;5(1):9-13

9 Chen M-Y. Misperception of oral health among adults in rural areas: a fundamental but neglected issue in primary healthcare. Int J Environ Res Public Health 2018;15(10):2187

10 Herzberg MC, Weyer MW. Dental plaque, platelets, and cardiovascular diseases. Ann Periodontol 1998;3(1):151-160

11 Tonetti MS, Van Dyke TE; working group 1 of the joint EFP/ AAP workshop*. Periodontitis and atherosclerotic cardiovascular disease: consensus report of the Joint EFP/AAP Workshop on Periodontitis and Systemic Diseases. J Periodontol 2013;84(Suppl 4S):S24-S29

12 Bosy A. Oral malodor: philosophical and practical aspects. J Can Dent Assoc 1997;63(3):196-201

13 Scully C, Greenman J. Halitology (breath odour: aetiopathogenesis and management). Oral Dis 2012;18(4):333-345

14 Ahmad FA, Alotaibi MK, Baseer MA, Shafshak SM. The effect of oral health knowledge, attitude, and practice on periodontal status among dental students. Eur J Dent 2019;13(3):437-443

15 Moore C, Addy M. Wear of dentine in vitro by toothpaste abrasives and detergents alone and combined. J Clin Periodontol 2005;32(12):1242-1246

16 Witt JJ, Walters P, Bsoul S, Gibb R, Dunavent J, Putt M. Comparative clinical trial of two antigingivitis mouth rinses. Am J Dent 2005; 18(Spec No) :15A-17A

17 Turssi CP, Messias DCF, de Menezes M, Hara AT, Serra MC. Role of dentifrices on abrasion of enamel exposed to an acidic drink. Am J Dent 2005;18(4):251-255

18 Manly RS, Wiren J, Manly PJ, Keene RC. A method for measurement of abrasion of dentin by toothbrush and dentifrice. J Dent Res 1965;44(3):533-540
19 Van der Weijden FA, Campbell SL, Dörfer CE, González-Cabezas C, Slot DE. Safety of oscillating-rotating powered brushes compared to manual toothbrushes: a systematic review. J Periodontol 2011;82(1):5-24

20 Robinson PG. The safety of oscillating-rotating powered toothbrushes. Evid Based Dent 2011;12(3):69

21 Abrams K, Caton J, Polson A. Histologic comparisons of interproximal gingival tissues related to the presence or absence of bleeding. J Periodontol 1984;55(11):629-632

22 Caton JG, Polson AM. The interdental bleeding index: a simplified procedure for monitoring gingival health. Compend Contin Educ Dent 1985;6(2):88, 90-92

23 Thilo BE, Caton JG, Polson AM, Espeland MA. Cell populations associated with interdental gingival bleeding. J Clin Periodontol 1986;13(4):324-329

24 Carter HG, Barnes GP. The gingival bleeding index. J Periodontol 1974;45(11):801-805

25 Grantham-McGregor S, Cheung YB, Cueto S, Glewwe P, Richter L, Strupp B; International Child Development Steering Group. Developmental potential in the first 5 years for children in developing countries. Lancet 2007;369(9555):60-70

26 Sood S, Ahuja V, Chowdhry S. Reconnoitring the association of nutritional status with oral health in elementary school-going children of Ghaziabad City, North India. J Indian Soc Pedod Prev Dent 2014;32(3):197-201

27 Bastos JL, Peres MA, Peres KG, Barros AJ. Infant growth, development and tooth emergence patterns: a longitudinal study from birth to 6 years of age. Arch Oral Biol 2007;52(6):598-606

28 Çolak H, Dülgergil ÇT, Dalli M, Hamidi MM. Early childhood caries update: a review of causes, diagnoses, and treatments. J Nat Sci Biol Med 2013;4(1):29-38

29 Mennella JA, Bobowski NK, Reed DR. The development of sweet taste: from biology to hedonics. Rev Endocr Metab Disord 2016;17(2):171-178

30 Mehrotra V, Garg K, Sharma P, Sajid Z, Singh R. A study based on Dental awareness, knowledge and attitudes among the medical practitioners in and around Kanpur city (india). J Interdiscipl Med Dent Sci. 2015 Jul;3(4):1-9.

31 Jagan P, Fareed N, Battur H, Khanagar S, Manohar B. Conceptual knowledge of oral health among school teachers in South India, India. Eur J Dent 2018;12(1):43-48

32 Reddy LR, Lavanya R, Saimadhavi N, Ramesh T, Jyothirmai K, Reddy PM, Saikiran C. Oral hygiene practices and habits among dental students and staff in a dental college, India. Cumhuriyet Dental Journal. 2014;17(1):7-13 